\title{
Shear Deformation Characteristics of Aeolian Sand in Gurbantunggut Desert
}

\author{
Chang-ning $\mathrm{JIN}^{1, \mathrm{a}^{*}, \text { Yu-hong ZHANG }}{ }^{2, \mathrm{~b}}$ \\ ${ }^{1}$ Foshan University, Foshan, Guangdong, China \\ ${ }^{2}$ Foshan University, Foshan, Guangdong, China \\ aemail:xjjcnalt@163.net, bemail:zyh@fosu.edu.cn
}

Keywords: Road Engineering; Shear Deformation; Aeolian Sand; Desert; Gurbantunggut Desert Abstract: Through various types of quick shear test, completely grasp the shear deformation characteristic of aeolian sand in Gurbantunggut Desert. The test result shows that the shear deformation curve of aeolian sand is influenced obviously by relative compactness. When the latter one is lower than $95 \%$, the peak doesn't appear; when being greater than $95 \%$, the peak value may appear frequently. With increase of compactness and vertical pressure, the differential value between peak shear strength and residual shear strength also increase; the influence on residual shear strength by compactness, vertical pressure and water content rate is less, the greater influence mostly appears when the peak shear strength is over $90 \%$, showing that the aeolian sand is provided with obvious shear dilatancy and shear contraction. Under unsaturated water while testing, the shear strain is between $0.64 \% \sim 1.12 \%$ when the peak value appears; Under unsaturated water while testing, the shear strain may increase obviously so as to cause that the peak value for shear deformation curve uneasily appears. The mechanism lies in the complicated change and comprehensive influence of connection between capillary force and film water caused by change of compactness and water content ratio.

\section{Preface}

In order to completely grasp the pavement performance of aeolian sand especially for subgrade strength characteristics, the sampling shall be conducted on the fixed $\sim$ semi-fixed tall sand dune in the southeast of Gurbantunggut Desert to perform the direct shear test (quick shear test) for various types of sandy soil.

Table 2. Particle composition of aeolian sand

\begin{tabular}{cc}
\hline Particle diameter $/ \mathrm{mm}$ & Passing rate $/ \%$ \\
\hline 1.18 & 99.4 \\
0.5 & 87.3 \\
0.25 & 54.7 \\
0.15 & 31.8 \\
0.1 & 22.0 \\
0.074 & 15.6 \\
0.05 & 9.5 \\
0.02 & 5.3 \\
0.01 & 1.4 \\
0.005 & 1.1 \\
0.002 & 1.1 \\
\hline
\end{tabular}

Table 1. Mineral composition in aeolian sand

\begin{tabular}{ccc}
\hline Mineral name & $\begin{array}{c}\text { Content } \\
/ \%\end{array}$ & $\begin{array}{c}\text { Particle diameter } \\
/ \mathrm{mm}\end{array}$ \\
\hline Quartz & 49 & $0.05 \sim 0.3$ \\
Plagioclase & 15 & $0.06 \sim 0.25$ \\
Microcline & 3.7 & $0.1 \sim 0.25$ \\
Potash feldspar & 3 & $0.1 \sim 0.25$ \\
Phyllite debris & 2 & $0.1 \sim 0.2$ \\
Mudstone debris & 3.5 & $0.1 \sim 0.2$ \\
Mudstone debris & 4.7 & $0.05 \sim 0.1$ \\
Eruptive rock debris & 17 & $0.1 \sim 0.2$ \\
intermediate acidity & 1 & $0.05 \sim 0.1$ \\
Magnetite & $<1$ & 0.05 \\
Limonite & $<1$ & $0.05 \sim 0.1$ \\
Tourmaline & $<1$ & 0.05 \\
Epidote & $<1$ & $0.03 \sim 0.05$ \\
Zircon & $<1$ & 0.05 \\
Sphene & 1 & $0.1 \sim 0.25$ \\
Amphibole & &
\end{tabular}

In the Gurbantunggut Desert Hinterland, the variation of mineral composition and grain composition is less (Table 1 Table 2), with 2.65 for relative specific gravity of soil particle, $1.987 \mathrm{~g} / \mathrm{cm}^{3}$ for maximal dry density, $1.508 \mathrm{~g} / \mathrm{cm}^{3}$ for minimum dry density, the permeability coefficient is between $5.0 \sim 5.9 \mathrm{~m} / \mathrm{d}$ when the compactness is $100.1 \% \sim 91.4 \%$, and the rise height of capillary water is between $53 \sim$ $59 \mathrm{~cm}$.It is compared with other deserts in our country that the main difference lines in more coarse particle relatively (about $0.24 \mathrm{~mm}$ for average particle diameter), being of most coarse aeolian sand in our country (the mean particle diameter of aeolian sand in our country's desert) is between $0.093 \mathrm{~mm} \sim$ 
$0.234 \mathrm{~mm}$ ), the shear deformation characteristic not only is provided with representativeness but also is provided with particularity[1].

\section{Introduction to Test Design}

Whereas the primary factor influencing the soil mass deformation is compactness, based on actual stress condition while forming of aeolian sand and in accordance with the requirement of "Surface Vibrating Compaction Tester Method(T0133-93)" in Test Methods of Soils for Highway Engineering (JTJ051-93), the test result performed during earlier stage refers to Figure 1, it may be observed that the aeolian sand is

provided with obvious compactness characteristic, presenting that the compactness curve presents the concave, when the water content ratio is extreme low (zero or close to zero) or being saturate, the aeolian sand is provided with the dry density maximum respectively, however, when the water content ratio is between $2 \% \sim 6 \%$, the dry density minimum appears, what's more, the difference value between maximal dry density and minimum dry density is also little, only being of about $0.1 \mathrm{~g} / \mathrm{cm}^{3}$.

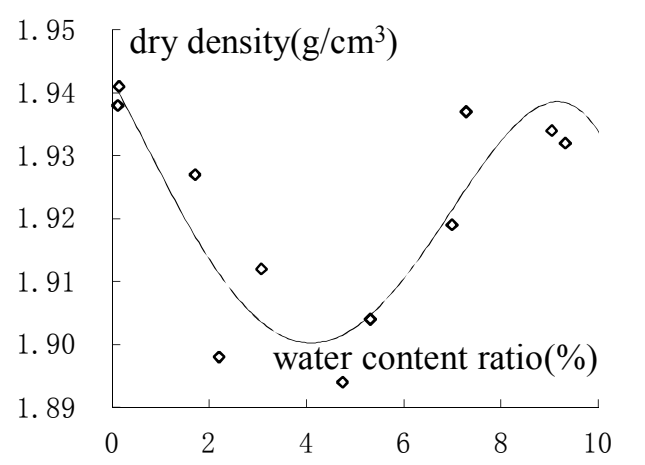

Table 3. Water content ratio and controlled (maximal) dry density

\begin{tabular}{cccc}
\hline Test combination & A & B & C \\
Water content ratio $/ \%$ & 0 & 4.5 & 8 \\
Dry density $/ \mathrm{g} \cdot \mathrm{cm}^{-3}$ & 1.94 & 1.91 & 1.93 \\
\hline
\end{tabular}

Figure 1. Vibrating compaction curve of aeolian sand

The test combination selected by Figure 1 refers to Table 3. While selecting various compactness and water content ratio, whether there is water saturation difference while testing. The test scheme not only can guarantee that the parameter variation conforms to the comprehensiveness and certain span requirement but also cover all characteristic points on the compactness curve. It is required to be described that the controlled dry density listed in Table 3 is served as compactness $100 \%$ uniformly for three kinds of test combination, namely, the vibrating compactness in Figure 1 is also served as maximal compacted dry compactness (100\% compactness) corresponding to different water content ratios, therefore, for different test combinations, even if the compactness is same, the dry density isn't may be same.

Table 4. Test type and parameters

\begin{tabular}{|c|c|c|c|c|c|c|c|c|c|c|c|}
\hline Type No. & A1 & $\mathrm{A} 2$ & A3 & B1 & B2 & $\mathrm{A} 1 *$ & $\mathrm{~A} 2 *$ & A $3 *$ & $\mathrm{~A} 4 *$ & $\mathrm{~B} 1 *$ & $\mathrm{~B} 2 *$ \\
\hline Compactness $/ \%$ & 90 & 95 & 100 & 90 & 95 & 90 & 95 & 100 & 105 & 90 & 95 \\
\hline Type No. & B3 & B4 & $\mathrm{C} 1$ & $\mathrm{C} 2$ & $\mathrm{C} 3$ & $\mathrm{~B} 3 *$ & B4* & $\mathrm{C} 1 *$ & $\mathrm{C} 2 *$ & $\mathrm{C} 3 *$ & $\mathrm{C} 4 *$ \\
\hline Compactness $/ \%$ & 100 & 102 & 90 & 95 & 100 & 100 & 105 & 90 & 95 & 100 & 105 \\
\hline Remarks & $\begin{array}{l}\text { Maxin } \\
\text { refer } t \\
\text { testing }\end{array}$ & $\begin{array}{l}\text { dry d } \\
\text { ble } 3 \\
\text { s test }\end{array}$ & $\begin{array}{l}y \text { and } \\
\text { unse } \\
\text { amed }\end{array}$ & $\begin{array}{ll}\mathrm{rcc} \\
\mathrm{ed}\end{array}$ & $\begin{array}{l}\text { t ratio } \\
\text { while } \\
\text { short. }\end{array}$ & \multicolumn{6}{|c|}{$\begin{array}{l}\text { Maximal dry density and water content ratio } \\
\text { refer to Table } 3 \text {. It is saturated water while } \\
\text { testing, this test is named as Grade II for } \\
\text { short. }\end{array}$} \\
\hline
\end{tabular}

Based on "Direct Shear Test for Sandy Soil(T0133-93)" in Test Methods of Soils for Highway Engineering (JTJ051-93), the direct shear apparatus with strain control shall be selected. In order to maximally eliminate the influence by apparatus factor, all tests shall be performed on one apparatus uniformly. For ones with unsaturated water while testing, according to the regulation requirement, the selected vertical pressure covers such five grades as $50 \mathrm{kPa}, 100 \mathrm{kPa}, 200 \mathrm{kPa}, 300 \mathrm{kPa}$ and $400 \mathrm{kPa}$, 
however, for ones with saturated water while testing, the comparison gives priority, the selected vertical pressure is such two grades as $100 \mathrm{kPa}$ and $200 \mathrm{kPa}$. The test type refers to Table 4 . While testing the sample during forming, it is found that the compactness is very easy to reach $90 \%$ and isn't also difficult to exceed $100 \%$. Through considering the influence by various factors, the selected compactness differential is 5\%, with Grade III to Grade IV for number of grade: $90 \%, 95 \%, 100 \%$ and $>100 \%$ (having Grade $0 \sim 1$ ).

\section{Test Result and Analysis}

The test result refers to Figure 2. X-coordinate in the figure is shear displacement $\delta$, with $0.01 \mathrm{~mm}$ for unit; Y-coordinate is shear strain $\Gamma$, with $\mathrm{kPa}$ for unit; the water content ratio $\omega$ and compactness $\lambda$ refer to Table $4 . \diamond, \square, \triangle, \times$ and + respectively indicates that the vertical pressure is $50 \mathrm{kPa}, 100 \mathrm{kPa}$, $200 \mathrm{kPa}, 300 \mathrm{kPa}$ and $400 \mathrm{kPa}$ while shearing test.
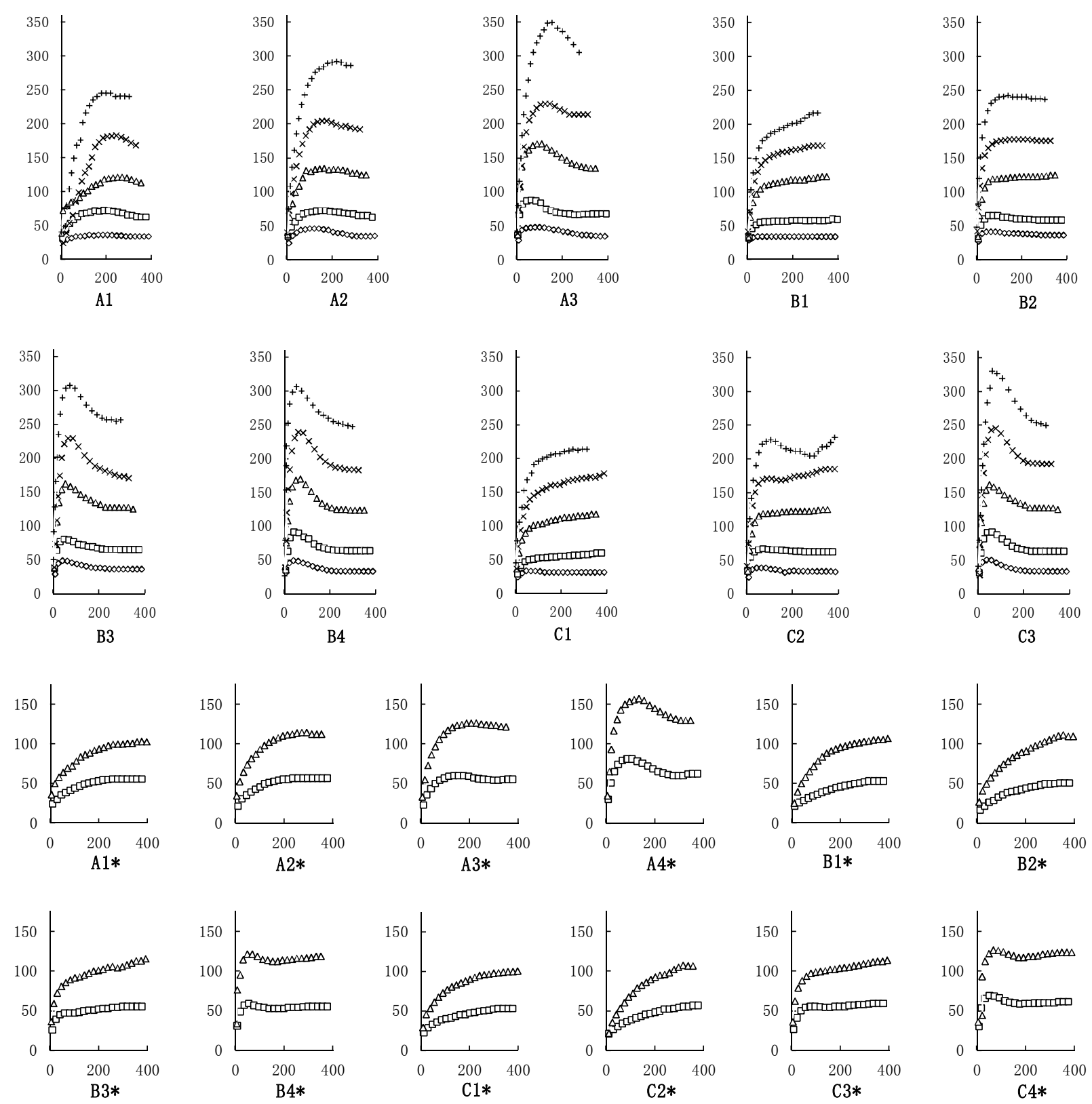

Figure 2. Shear strain and shear deformation curve for various quick shear tests 
It may be observed that:

(1) For Category I, there is similar discipline for various tests; when the compactness I is lower, such as, $\leq 95 \%$, the peak value doesn't appear basically for shear deformation curve, the one that appears occasionally also is the one with relatively higher compactness (for example: $95 \%$ ) or greater vertical pressure; when the compactness is greater, such as, $\leq 95 \%$, the he peak value may appear basically for shear deformation curve, with increase of compactness and vertical pressure, the peak value is also more obvious.

Above-said phenomena shows that the shear deformation characteristic of aeolian sand doesn't completely depend on the absolute value of density but also is obviously influenced by change of water content ratio meanwhile[2].

The water content ratio notably influences the compactness characteristic of aeolian sand to cause that the compact curve presents very particular concavity (Figure 1). The mechanism lines in: when the water content ratio is zero or is close to zero, the dry sand particle easily inlays mutually and tightly ranks, the dry density achieved by rolling compaction is great, being of maximum frequently; with increase of water content ratio, on one aspect, the film water (bound water) existing on the sand particle surface produces the weaker water connection among sand particles, one the other aspect, capillary water appears to cause weaker capillary tension as well, both of them are functioned by force to uniformly resist the change and impede mutual approach of intermediate sand particle in the process of rolling compaction so that the dry density achieved by rolling compaction lowers obviously; with further increase of water content ratio, thicker film water may enable that the water connection weakens, however, more capillary water enables that the capillary tension is strengthened, both mutually-resisted ones function jointly to enable that not only the dry density achieved from rolling compaction is minimum frequently but also the variation amplitude is not great and the curve is more gentle[3]; after that, when the water content ratio further increases, the film water thickens, however, the increase of capillary tension is also limited and reaches the maximum while being certain water content ratio, subsequently, with further increase of water content ratio, the capillary tension weakens since the capillary water fills into thicker capillary and quantity reduces so that the compacted dry density increases persistently[4]; after the water content ratio saturates, the capillary tension disappears, very thin water film is also weak for water connection of sand, however, the lubrication function of sand grain moving is more beneficial for tight inlaying of sand particle on the contrary, therefore, the maximal dry density may also be achieved for rolling compaction.

The influence on shear deformation characteristic by water content ratio is identical to influence on compaction characteristic on mechanism so as to cause that the shear deformation curve of aeolian sand presents more complicated variation. On the one hand, with increase of water content ratio, the shear of aeolian sand turns towards "plasticity" from "brittleness" (namely, the peak shear strength appears when the shear displacement is less) on the other hand, the most obvious "brittleness" doesn't indicate that the water content ratio is zero, however, when the water content ratio is $4.5 \%$, the dry density for compactness is minimum. The influence on shear deformation characteristic by compactness conforms to general discipline, namely, when the water content ratio is definite, the greater the compactness, the stronger the "brittleness", in addition, its influence is obviously greater than the influence by water content ratio. Under joint functioning of compactness and water content ratio, whether the peak value appears for shear deformation curve depends on relative compactness rather than absolute density[5].

(2) When the peak value doesn't appear for shear deformation curve, the shearing stress is taken as the temporary shearing strength when the curve is gentle (horizontal or approximately horizontal); when there is peak value, the shearing stress corresponding to this is peak shear strength; the shear stress is residual shear strength when the curve tends to gentle (horizontal or approximately horizontal) after peak value. For Category I in three kinds of shear strength, regardless of test combination, there is similar discipline uniformly: firstly, after the peak value appears for shear deformation curve, with increase of compactness and vertical pressure, the difference value between peak shear strength and residual shear strength also increases obviously, and the shear strain when the peak value appears also 
increases obviously with increase of vertical pressure; secondly, although the residual shear strength and critical shear strength show the increase tendency with increase of compaction or vertical pressure, however, the tendency isn't obvious, and the influence by different water content ratio is even less; additionally, the residual shear strength and critical shear strength of aeolian sand is also higher generally, being over $90 \%$ of peak shear strength mostly.

Above phenomenon indirectly shows that, the aeolian sand is provided with more obvious shear dilatancy and shear contraction same as common sandy soil, namely, after shear failure, the density at the shear surface (or relative compactness) is consistent basically; if the density before shear failure (or relative compactness) is greater, the density at the shear surface (or relative compactness) may lessen (from denseness to looseness) after shear failure; if the density before shear failure (or relative compactness) is less, the density at the shear surface (or relative compactness) may largen (from looseness to denseness) after shear failure; the achieved relative compactness thereout is between $95 \% \sim 100 \%$ mostly for aeolian sand, the one close to $95 \%$ is in the majority.

Above phenomenon also shows from the other side that, since there are shear dilatancy and shear contraction, the compactness, vertical pressure and water content ratio are provided with certain influence on critical shear strength and residual shear strength of aeolian sand, however, the influence isn't great; while the peak shear strength irrelevant with shear dilatancy and shear contraction is positively relevant with compactness and vertical pressure obviously. The shearing resistance of aeolian sand finally shown by superposition of two kinds of factor remains positively relevant with compactness and vertical pressure obviously[6].

(3) For Category I, when the peak value appears for shear deformation curve, the shear strain when the peak value increases obviously with increase of vertical pressure, especially when the compactness is higher, however, the variation amplitude isn't great, for example, when the vertical pressure increases up to $400 \mathrm{kPa}$ from $50 \mathrm{kPa}$, the shearing deformation corresponding to the peak value increases around $0.7 \mathrm{~mm}$ from around $0.4 \mathrm{~mm}$, and the converted shear strain is between $0.64 \% \sim 1.12 \%$. For Category II, since there only is test data that the vertical pressure is $100 \mathrm{kPa}$ and $200 \mathrm{kPa}$, the complete analysis and comparison can't be performed, however, it can also be observed that, through comparison with Category I, the shear deformation corresponding to peak value has increased obviously, and the difference value between peak shear strength and residual shear strength obviously has lessened obviously so as to cause that the peak value for shear deformation curve is difficult to appear consequently.

On one hand, above phenomenon shows that the aeolian sand with scattered granular texture shows the "brittleness" obviously during shear deformation, and when the "confining pressure" increases, the "plasticity" also increases; on the other hand, above phenomenon also shows that the saturated water while testing eliminates the capillary and the water lubrication function can obviously increase the "plasticity" of aeolian sand after connection of film water[7].

(4) Through comparing Category II and Category I, the residual shear strength is lower generally (the peak shear strength is also low and more obvious even). It is shown that, while performing the shear test of aeolian sand, whether the water saturates may produce certain influence on test result while testing. This kind of influence is from the difference between water lubrication function (saturated) and connection function (when there is certain water content ratio) of capillary tension and film water or dry friction (when the water content is zero). Although the shear strength variation caused by this kind of difference isn't great in general, however, the comparatively complicated variation shown in Figure 2 may also be caused.

Above-said test achievement has been used for guiding the engineering practice. For instance, the compactness of aeolian sand may be $95 \%$ or slightly higher, higher compactness only improves and can't remain the peak strength all along, only increasing the" brittleness". It is discovered that the one to decide the strength of aerolian sand is relative compactness but not absolute compactness, it can be known hereby that the water stability of dry compaction technology for aerolian sand subgrade is guaranteed, the cause is that the density is maximal during dry compaction of aeolian sand, the water content ratio increases due to water immersion so as to increase the relative compactness on the 
contrary. Some researchers have ever found through testing on the site after the desert highway has run for several years that the elastic modulus of aeolian sand subgrade is farther greater than the value while designing, thus, proposing that the design value should be improved. However, we deem based on this test result that the reason is caused by driving for many years to cause higher compactness and produce higher peak strength, however, the latter one can't be remained all along and so on[8].

\section{Conclusion}

(1) The coarse particle of aeolian sand in Gurbantunggut Desert is more on content and is most coarse in our country's aeolian sand as well as is provided with obvious dry compactness characteristic, showing that the compaction curve presents the concave. When the water content ratio is extreme low (zero or close to zero) or saturated, there is dry density maximum respectively. When the water content ratio is $3 \% \sim 6 \%$, the dry density minimum may appear, in addition, the difference value between maximal and minimal dry density is not great, only being of about $0.4 \mathrm{~g} / \mathrm{cm}^{3}$.

(2) The shear deformation curve of aeolian sand is obviously influenced by the relative compactness -when the relative compactness is lower than 95\%, the peak value doesn't appear basically; when the compactness is higher than $95 \%$, the peak value may appear frequently and increase with increase of compactness and vertical pressure, and the differential value between shear strength and residual shear strength also increases. The residual shear strength is less influenced by the compactness, vertical pressure and water content ratio, the value is higher generally, being over $90 \%$ of peak shear strength mostly. While testing, there is unsaturated water, the appearing peak shear stain is between $0.8 \%$ $1.6 \%$ mostly; While testing, the saturated water may increase obviously as that the peak value doesn't appear easily.

(3) The test result indirectly shows that the aeolian sand has obvious shear expansion and shear contraction. Additionally, the mechanism analysis shows that the shear deformation characteristic of aeolian sand is mainly influenced by functioning of water lubrication (while saturated water), capillary tension and film water connection (when there is certain water content ratio) and dry friction (when the water content is zero) caused by relative compactness, vertical pressure and variation of water content ratio. Although the variation of shear strength caused by different functions isn't great in general, the comparatively complicated variation may cause.

Above-said test achievement may be used for determining the compactness of aeolian sand, analyzing the water stability as well as determining the valuing method for elastic modulus design value of subgrade.

\section{References}

[1] JIN Chang-ning, LI Zhi-nong, ZHANG Deng-liang, et al. Study of the Road Usability of Wind Blown Sand in Desert Areas(in Chinese)[R]. Xinjiang Communication Scientific Research Institute. 2003.

[2] CHI Ming-jie, ZHAO Cheng-gang, LI Xiao-jun. Stress-dilation mechanism of sands[J].China Civil Engineering Journal,2009,42(3):99-104.

[3] ZHANG Jian-min. Reversible and irreversible dilatancy of sand[J].Chinese Journal of Geotechnical Engineering,2000,22(1):12-17.

[4] CHANG Zai, YANG Jun, CHENG Xiao-hui. Granular mechanical analysis of the strength and dilatancy of sands[J].Engineering Mechanics,2010, 27(4):95-103.

[5] LIU Yang, ZHOU Jian, WU Shun-chuan. Micro-numerical simulation of cyclic biaxial test I: results of loose sand[J].Chinese Journal of Geotechnical Engineering,2007,29(7):1035-1041.

[6] LIU Yang, ZHOU Jian, WU Shun-chuan. Micro-numerical simulation of cyclic biaxial test II: results of dense sand[J].Chinese Journal of Geotechnical Engineering,2007,29(11):1676-1682. 
[7] LIU Qing-bing, XIANG Wei, B.M.Lehane, et al. Experimental study of effect of particle shapes on shear strength of sand and tip resistance of driven piles[J].Chinese Journal of Rock Mechanics and Engineering,2011,30(2):400-410.

[8] JIN Chang-ning, ZHANG Yu-hong, LI Sen, et al. Influence of Change in Plasma on Compaction Features of Wind-Formed-Sand[J]. Journal of Highway and Transportation Research and Development,2008,25(10):36-40. 